\title{
Instructional Selection of Active Learning and Traditional Courses Increases Student Achievement in College Mathematics
}

\author{
John Paul Roop ${ }^{1}$, Kossi Edoh ${ }^{1} \&$ Alexandra Kurepa ${ }^{1}$ \\ ${ }^{1}$ Department of Mathematics, North Carolina A\&T State University, Greensboro, NC 27411, USA \\ Correspondence: John Paul Roop, Department of Mathematics, 102 Marteena Hall, North Carolina A\&T State \\ University, Greensboro, NC 27411, USA.
}

Received: May 28, 2018

Accepted: June 12, 2018 Online Published: June 18, 2018

doi:10.5539/jel.v7n5p11

URL: https://doi.org/10.5539/jel.v7n5p11

Dr. Edoh was partially supported by NSF HRD-1719498 and NSA H98230-18-1-0097. Dr. Kurepa was partially supported by NSF award number DUE-1259900.

\begin{abstract}
In this paper, we present the results of a study indicating that groups predominantly underrepresented in mathematics prefer to have a choice of instructional method. We use the concept of differentiated instruction to explain how different groups of students might perform better using various instructional techniques. Our study, which is based on student self-selection of traditional or active learning sections of a course, also presents evidence that using different instructional strategies in different sections of the same course is preferable to adopting only a single instructional method. In addition, we present evidence that student instructional selection improves student achievement in college level mathematics courses.
\end{abstract}

Keywords: active learning, differentiated instruction, course redesign, college mathematics

\section{Introduction}

Many lower level university courses are taught using instructional strategies that limit one-on-one or small group interaction. For many years, the model at large universities was the large auditorium lecture section. In recent years, universities have turned to online courses as both a cost saving strategy and as a way of broadening the financial base.

Of major concern are the high failure rates among underserved students in lower-level, general education mathematics courses. An estimated 60 percent of students in public institutions fail to complete their degrees, of which half leave during their freshman year (Twigg, 2005). Making significant improvement in gatekeeper courses can have a major impact on student success and retention. Many students can succeed in the traditional large lecture sections and may even prefer online sections, but in order to guarantee student success and satisfaction, sections incorporating active learning or "flipped classroom" strategies must be offered.

In the last decade, significant research developments have taken place in the way mathematics is taught in general education mathematics courses. These developments appear in areas of broad interest and relevance to students in many disciplines (Freeman et. al, 2014). Bonwell (1991) defines active learning in the following way:

(1) Students are involved in more than listening

(2) Less emphasis is placed on transmitting information and more on developing students' skills

(3) Students are involved in higher-order thinking (analysis, synthesis, evaluation)

(4) Students are engaged in activities (e.g. reading, discussing, writing)

(5) Greater emphasis is placed on students' exploration of their own attitudes and values (Bonwell, 1991).

Educational theory suggests that different instructional methods benefit a diverse student population. Active learning methods have been suggested as an alternative for minority students to traditional lecture-based classes. While active learning strategies may benefit some students, others prefer a traditional lecture-based course. Engaging students in active learning and technology could potentially increase the excitement of non-traditional and minority students. Studies have shown that minority students tend to perform better in active learning 
environment rather than using traditional lecture structures. (Eddy and Hogan, 2014, Graham, 2013, Ross, 2014, Edoh et. al., 2017)

In Section 2, we review the educational theory behind various instructional strategies in mathematics and science courses. In Section 3, we give the research hypotheses and the rationale for the study. In Section 4, we detail the course redesign and experimental setup for the active learning implementation of an applied calculus course. In Section 5, we discuss the results of a survey given to students in both active learning and traditional sections. In Section 6, we give the results of a statistical study into the student success of the traditional courses verses the active learning courses. Finally, in Section 7, we give the conclusions and future work.

\section{Educational Theory}

Questions about the supremacy of lecture-based instruction methods in college courses have been asked for over forty years, since the mid-to-late 1970s. A study published in 1975 found that students who did not attend lecture but instead received a typed transcript of the lecture showed no significant difference in performance on exams than students who attended the lecture (Northcraft and Jernstedt, 1975).

In the field of mathematics, the method of most notoriety which excludes lecture is the method of R.L. Moore in which students themselves construct the material (Jones, 1977). As most active learning techniques are intended to address a diverse student body, the Moore method has been criticized by minorities (Marshall et. al., 2007).

The idea of differentiated instruction originated in the public school system in which students of various levels of preparation and ability must be taught by the same teacher in the same classroom. Differentiated instruction arose out of sheer necessity because some students in the class were unresponsive to traditional lecturing. Since that time numerous research studies have appeared that suggest individuals don't learn the same way (Subban, 2006 and Fischer, 2001).

Differentiated instruction is the concept that multiple avenues should be given for teaching and assessment. Differentiated instruction addresses education of students with varying ability levels and cultural backgrounds. It is expected that teachers should use different instructional styles and educational support material to allow for students with various learning styles to succeed. Processes that lead to success in differentiated instruction include providing additional supports, assistive technology, encouraging independence, and using personal assistance, for example team learning and peer tutoring (Lawrence, 2004).

Differentiated learning research studies are composed of two main types. One type of research in the area of differentiated instruction lies in brain and learning research (Green, 1999). Another approach to differentiated instruction research lies in enhancing the educational workspace or classroom enhancements (Kolb, 2005). Such classroom improvements range from technology, including $3 \mathrm{~d}$ printers, to maker space environments where much money has been used to transform media centers into creative studios (Dougherty, 2012).

One of the main ideas behind differentiated instruction is that an instructor should choose whichever pedagogical technique seems to be working at the time (Corno, 2008). A well-prepared teacher should be prepared to use any of a number of instructional styles in order to reach $21^{\text {st }}$ century learners. Finally, research suggests that minority students have a different learning mentality and respond better to active learning and experiential learning rather than traditional lecturing (Irvine, 1995).

The idea of differentiated instruction shows promise in improving instruction at the collegiate level, especially in the area of mathematics (Chamberlain, 2010). As students in colleges are differentiated in any number of ways, including class schedule and academic major, differentiated instruction can be implemented on a broader scale. In college courses, especially general education and mathematics courses, multiple sections are offered each term. One way that differentiated instruction can be actuated in higher education is by offering course sections that provide differentiated instructional selection. In the next section, we offer two research hypotheses aimed at answering the questions regarding the effectiveness of differentiated instruction in the context of instructional selection.

\section{Research Hypotheses}

Research hypothesis 1: Students have a preference between the traditional instructional methods and active learning instructional methods.

Research hypothesis 2: Students' choice between instructional methods increases performance overall.

The first research hypothesis concerns students' preference between the traditional lecturing method of instruction and an active learning method. We conjecture that among the general population of college students, 
some subset of those students may prefer an instruction style that emphasizes active learning more so than the traditional method.

The differentiated classroom or differentiated learning method is widely included as a part of required coursework for a teacher education program in order for a future teacher to be certified to teach in the public school system of that particular state. We conjecture that one significant mechanism is that the school system primes students for instruction using the active learning instruction method. Some college students may prefer active learning pedagogies as a carry over from high school. Regardless of what method might have been preferred in the past decades or might be preferred by instructors, we conjecture that many students who are matriculating from the public school system are primed to prefer active learning pedagogies.

When only traditional lecturing sections of a particular course are offered, it is anticipated that a percentage of students would be dissatisfied with the instructional method because such an educational setting is one for which they have developed an aversion. However, when only active learning sections of a particular course are offered it is not clear whether students who would prefer a traditional classroom would be as dissatisfied.

We hypothesize that students who self-select the active learning classroom would exhibit a stronger preference for active learning than students who self-select the traditional classroom exhibit towards that instructional method. We hypothesize that either offering only active learning sections or a mixture of active learning sections would increase passing rates over courses which offer only traditional sections.

We conjecture that offering a mixture of active learning and traditional sections is preferable for two main reasons. One possible reason is that many faculty members are not familiar with active learning pedagogies and would prefer traditional lecturing. Many faculty members would essentially have to be retrained. Faculty members have academic freedom and due process, and so it is not clear if such an intense and costly retraining is even possible.

Another very important reason for offering a mixture of sections is that active learning sections are costlier than lecture sections. Active learning requires more engagement, preparation, and time working one-on-one with students. In the next section, we discuss our implementation of the instructional selection between traditional and active learning sections, and give the methodology by which we test the stated research hypotheses.

\section{Methodology}

In order to test the first research hypothesis, we developed and implemented a survey given to both an active learning section and a traditional lecture section of the same course taught by the same instructor during the same term. Students registering for the course self-selected the section of the course section for which they registered. In order to test the second research hypothesis, we examine pass rates of the course overall when only traditional sections were offered and again when all traditional sections were offered except one active learning section.

The redesigned course considered in this paper is a general education applied calculus course targeted at students in Technology, Business, Agriculture and the Health Sciences. The class in question is composed of traditional and non-traditional (adult/online) students. The overwhelmingly majority are from protected minority groups. For the majority of our students, the high expectation of them to do more reading on their own may be not be ideal. Thus, the students need more reinforcement and motivation that can be achieved through more active in-class lectures and just-in-time remediation. This is reinforced through the use of technology with more hands-on practice work in three ways: in class discussion of exercises, the workbook, and online homework assignments.

The redesign of the Math 112: Calculus for Business and Technology (annual enrollment of over 800) course follows that of the Student-Centered Active Learning Environment with the Upside-down Pedagogies model, which was developed by North Carolina State University. Our mathematics department has adopted the SCALE-UP (Beichner, 2007) model for our Calculus 1 course. The main distinction between SCALE-UP and traditional active learning ideas is the use of the active learning classroom, in which the classroom environment itself is altered to facilitate active learning (Park and Choi, 2014). The redesigned course has an equivalent three hours of lectures and an hour of roundtable active learning with interaction among students, GTAs and instructors. A workbook has been created for this course (Edoh et. al., 2016) and published by Pearson Publishing. In addition, worksheets are utilized during the interactive sessions.

\section{Survey and Results}

In order to assess the preference of students for active learning pedagogies versus traditional pedagogies, we deployed a survey in each of the active learning and traditional sections during the fall of 2017. Each survey was 
given to a group of 24 students. We used sections taught by the same instructor, so there is no instructor bias in the students' solicited responses.

Students were given ten questions inquiring their preference for active learning versus traditional in which responses were given using a five point Likert scale. For the active learning sections, questions were worded such as "I have a better attitude towards active learning than traditional" whereas for the traditional sections, questions were worded such as "I have a better attitude towards traditional than active learning".

In addition, students were asked six other questions. The first question inquires if students chose their section registration because of the instructional style. The remaining five inquire students' general study habits. The results from the survey are illustrated in Table 1. It is interesting to note that in all but two of the ten pedagogy questions, students in the active learning section indicated preference towards active learning, the exceptions being that the scale up model better prepares me for the real world (3.39) and the scale up model better helps me to remain focused (3.30).

Table 1. Survey results mean (standard deviation) of Math 112 students indicating preference for active learning sections versus traditional sections

\begin{tabular}{|c|c|c|}
\hline SCALEUP vs. Traditional questions & $\begin{array}{l}\text { Scale-UP } \\
\text { Section } \\
(n=24)\end{array}$ & $\begin{array}{l}\text { Traditional } \\
\text { Section } \\
(\mathbf{n}=\mathbf{2 4})\end{array}$ \\
\hline 1. I have a better attitude towards scale up than traditional. & $\begin{array}{l}4.09 \\
(1.16)\end{array}$ & $\begin{array}{l}2.96 \\
(1.23)\end{array}$ \\
\hline 2. It is easier to get a good grade from scale up than traditional. & $\begin{array}{l}3.61 \\
(1.27)\end{array}$ & $\begin{array}{l}2.92 \\
(0.97)\end{array}$ \\
\hline 3. It is easier to pass the class from scale up than traditional. & $\begin{array}{l}3.74 \\
(1.05)\end{array}$ & $\begin{array}{l}3.13 \\
(0.85)\end{array}$ \\
\hline 4. I would learn more from scale up than traditional lecture. & $\begin{array}{l}3.83 \\
(1.15)\end{array}$ & $\begin{array}{l}3.17 \\
(1.20)\end{array}$ \\
\hline 5. The scale up model better prepares me for the real world than the traditional model. & $\begin{array}{l}3.39 \\
(1.16)\end{array}$ & $\begin{array}{l}3.21 \\
(0.93)\end{array}$ \\
\hline 6. The scale up model better helps me to keep focused than the traditional lecture. & $\begin{array}{l}3.30 \\
(1.15)\end{array}$ & $\begin{array}{l}3.33 \\
(1.09)\end{array}$ \\
\hline 7. The scale up model better helps me to learn difficult material than traditional. & $\begin{array}{l}3.87 \\
(1.22)\end{array}$ & $\begin{array}{l}3.04 \\
(1.08)\end{array}$ \\
\hline 8. The scale up better helps me understand the big picture than traditional lecture. & $\begin{array}{l}3.78 \\
(1.09)\end{array}$ & $\begin{array}{l}3.33 \\
(1.01)\end{array}$ \\
\hline 9. The scale up model helps me to read the textbook better than the traditional. & $\begin{array}{l}3.48 \\
(1.20)\end{array}$ & $\begin{array}{l}3.63 \\
(1.13)\end{array}$ \\
\hline 10. The scale up model gives me a better sense of accomplishment than traditional. & $\begin{array}{l}3.74 \\
(1.14)\end{array}$ & $\begin{array}{l}3.17 \\
(1.05)\end{array}$ \\
\hline Other questions & $\begin{array}{l}\text { Scale-UP } \\
\text { Section }\end{array}$ & $\begin{array}{l}\text { Traditional } \\
\text { Section }\end{array}$ \\
\hline 11. I chose my course section based on my learning style. & $\begin{array}{l}3.70 \\
(1.26)\end{array}$ & $\begin{array}{l}2.96 \\
(1.12)\end{array}$ \\
\hline 12. I am a good note taker. & $\begin{array}{l}3.91 \\
(0.95)\end{array}$ & $\begin{array}{l}3.50 \\
(1.25)\end{array}$ \\
\hline 13. I am comfortable asking questions in class & $\begin{array}{l}3.78 \\
(1.13)\end{array}$ & $\begin{array}{l}4.08 \\
(1.02)\end{array}$ \\
\hline 14. I study on my own without being told. & $\begin{array}{l}3.65 \\
(1.11)\end{array}$ & $\begin{array}{l}3.75 \\
(1.33)\end{array}$ \\
\hline 15. I am good at using new software. & $\begin{array}{l}3.70 \\
(1.29)\end{array}$ & $\begin{array}{l}3.75 \\
(1.03)\end{array}$ \\
\hline 16. I have good reading comprehension skills. & $\begin{array}{l}4.22 \\
(1.00) \\
\end{array}$ & $\begin{array}{l}3.92 \\
(1.02) \\
\end{array}$ \\
\hline
\end{tabular}

Of the ten pedagogy questions given to the students in the traditional section, students indicated a preference towards the traditional pedagogy on only one question, that the traditional method better helps me to read the book (3.63). In all other nine questions, students show no preference to a very weak positive preference to the traditional instructional method. 
Whereas students in the scale up section are positively preferential towards that method, students in the traditional section show little to no preference. We can conclude from this that students register for the scale up section based on their preference.

In fact, in response to the question "I chose my course section based on my learning style", students in the scale up section responded with an average of 3.70, but students in the traditional section responded with an average of 2.96. This indicates that a subset of students self-select into the scale up section with the understanding that they would prefer that method of instruction.

Students in the traditional section answered marginally higher on the three general study skills questions "I am comfortable asking questions in class," "I study on my own without being told," and "I am good at using new software." However, students in the scale up section answered more positively to the question "I have good reading comprehension skills."

The first three of these questions indicate that the students in the traditional section are slightly more self-confident than students in the scale up section. However, it is not clear what the mechanism is behind the scale up students indicating stronger reading comprehension skills. Perhaps they are more interested in a distributed learning environment than an instructor centered learning environment.

Table 2. Demographic information of the composition of Math 112 classes in the study

\begin{tabular}{llll}
\hline & & Traditional & Scale-Up \\
\hline \multirow{3}{*}{ Gender } & Total Count & $\mathrm{n}=748$ & $\mathrm{n}=128$ \\
& Female & $401(54 \%)$ & $67(52 \%)$ \\
& Male & $347(46 \%)$ & $61(48 \%)$ \\
& Black or African American & $646(86 \%)$ & $112(88 \%)$ \\
& Hispanic & $28(4 \%)$ & $5(4 \%)$ \\
& White & $26(3 \%)$ & $3(2 \%)$ \\
\multirow{5}{*}{ Residency } & Two or More Races & $25(3 \%)$ & $4(3 \%)$ \\
& Other/Unknown & $23(3 \%)$ & $4(3 \%)$ \\
\multirow{3}{*}{ Clatussification } & In-State & $604(81 \%)$ & $100(78 \%)$ \\
& Out-of-State & $144(19 \%)$ & $28(22 \%)$ \\
& Continuing Student & $684(91 \%)$ & $116(91 \%)$ \\
& New/Returning & $64(9 \%)$ & $12(9 \%)$ \\
& Senior/Graduate & $60(8 \%)$ & $23(6 \%)$ \\
& Junior & $134(18 \%)$ & $66(52 \%)$ \\
\multirow{5}{*}{ Major } & Sophomore & $309(41 \%)$ & $29(23 \%)$ \\
& Freshman & $238(32 \%)$ & $2(2 \%)$ \\
& New Freshman & $7(1 \%)$ & $20(16 \%)$ \\
& Accounting & $90(12 \%)$ & $9(7 \%)$ \\
& Animal Science & $64(9 \%)$ & $28(22 \%)$ \\
& Management & $146(20 \%)$ & $13(10 \%)$ \\
& Marketing & $57(8 \%)$ & $50(39 \%)$ \\
& Other & $337(45 \%)$ & $8(6 \%)$ \\
\hline
\end{tabular}

\section{Statistical Study of Student Final Grade Data}

In order to examine student performance using the SCALE-UP active learning model, we performed a statistical study of student grades. On April 23, 2018, we received a data set from the Office of Institutional Research with data dating from the spring semester of 2016 to the fall semester of 2017 (two years). The SCALE-UP sections included three sections, one each in the fall of 2016, spring of 2017 and fall of 2017. Only sections taught by full-time faculty were considered, and online, evening, and summer courses were not considered.

The data set includes student grades in Math 112 with $\mathrm{n}=748$ students whose instructors used the traditional method and $\mathrm{n}=128$ students whose instructors used the SCALE-UP method. For each student, individual student records were provided that give the gender, race, in-state status, continuing student status, classification, major, before GPA, after GPA, SAT scores, ACT scores, and high school GPA.

Table 2 give the demographic information in the study which are coded as categorical variables. We see there is a slightly higher percentage of females in the traditional sections (54\% vs. 52\%) and a slightly higher percentage of black or African American students in the SCALE-UP sections ( $86 \%$ vs. $88 \%$ ). Also, there is a higher 
percentage of accounting (including finance) majors in the SCALE-UP sections (16\% vs. 12\%). These do play a role in the significance of the SCALE-UP method as in our study data, males outperformed females, black or African American students outperformed other demographic groups, and accounting majors were the top performers overall.

Table 3. Summary statistics (mean \pm standard deviation) and two-sample t-test statistics for course grades, high school grades and test scores

\begin{tabular}{|c|c|c|c|c|}
\hline & Traditional & Scaleup & t-value & p-value \\
\hline Math 112 Grade & $\begin{array}{l}1.90 \pm 1.32 \\
(\mathrm{n}=748)\end{array}$ & $\begin{array}{l}2.17 \pm 1.25 \\
(\mathrm{n}=128)\end{array}$ & 2.155 & 0.0157 \\
\hline HS GPA & $\begin{array}{l}3.32 \pm 0.52 \\
(\mathrm{n}=689)\end{array}$ & $\begin{array}{l}3.22 \pm 0.47 \\
(\mathrm{n}=121)\end{array}$ & -1.978 & 0.0241 \\
\hline SAT Reading & $\begin{array}{l}480.00 \pm 58.42 \\
(\mathrm{n}=527)\end{array}$ & $\begin{array}{l}481.94 \pm 53.78 \\
(\mathrm{n}=93)\end{array}$ & 0.299 & 0.3826 \\
\hline SAT Math & $\begin{array}{l}491.23 \pm 54.60 \\
(\mathrm{n}=528)\end{array}$ & $\begin{array}{l}492.04 \pm 52.91 \\
(\mathrm{n}=93)\end{array}$ & 0.133 & 0.4473 \\
\hline ACT Math & $\begin{array}{l}19.01 \pm 2.88 \\
(\mathrm{n}=327)\end{array}$ & $\begin{array}{l}17.97 \pm 2.64 \\
(\mathrm{n}=62)\end{array}$ & -2.640 & 0.0043 \\
\hline ACT Composite & $\begin{array}{l}18.56 \pm 2.87 \\
(\mathrm{n}=327)\end{array}$ & $\begin{array}{l}17.92 \pm 2.82 \\
(n=62)\end{array}$ & -1.6143 & 0.0536 \\
\hline Before GPA & $\begin{array}{l}2.79 \pm 0.64 \\
(\mathrm{n}=748)\end{array}$ & $\begin{array}{l}2.83 \pm 0.54 \\
(\mathrm{n}=128)\end{array}$ & 0.6675 & 0.2523 \\
\hline After GPA & $\begin{array}{l}2.73 \pm 0.64 \\
(\mathrm{n}=748)\end{array}$ & $\begin{array}{l}2.73 \pm 0.59 \\
(\mathrm{n}=128)\end{array}$ & 0 & 1.00 \\
\hline
\end{tabular}

Table 3 gives summary statistics information for the groups in the study (mean \pm standard deviation), and two-sample t-test statistics. We see there is a significant difference in the means of the traditional and SCALE-UP sections (1.9 traditional vs. 2.17 SCALEUP) with a significance level of $\mathrm{p}=0.0157$. Not all students took both the SAT and ACT tests since the admissions office offers students the choice between the college entrance exams. It is interesting to note that the traditional sections consist of significantly better prepared students (as entering freshmen): the traditional sections had an average high school GPA of 3.32 versus a 3.22 for SCALE-UP with a significance level of $\mathrm{p}=0.0241$. The traditional sections had average ACT math scores of 19.01 versus 17.97 for SCALE-UP with a significance level of $\mathrm{p}=0.0043$.

It is interesting to note that the traditional sections consist of more attractive students in terms of their college entrance statistics, but the SCALE-UP sections have a higher before university GPA (though not statistically significant). There seems to be some factor between the sets of students such that even though they performed worse on the ACT standardized tests, they are doing better in college. The data indicates that student attitude and motivation are factors for students deciding to enroll in a SCALE-UP section.

Table 4. Grade distribution for the traditional and SCALE-UP sections

\begin{tabular}{lll}
\hline Grade & Traditional & SCALE-UP \\
\hline A or A- & $7 \%$ & $9 \%$ \\
B, B + , or B- & $39 \%$ & $42 \%$ \\
C or C+ & $21 \%$ & $22 \%$ \\
D or D+ & $6 \%$ & $10 \%$ \\
F, W, or I & $27 \%$ & $17 \%$ \\
\hline
\end{tabular}

Table 4 gives the grade distributions of the traditional vs. SCALE-UP sections. We can see the SCALE-UP sections have higher percentages in all categories except F's (including withdraws and incompletes) where the failure rate in the traditional section was $27 \%$ and the failure rate in the SCALE-UP section was $17 \%$. One statistic used is the "DWF" rate. The DWF rate of the traditional sections was $33 \%$ and the DWF rate of the SCALE-UP sections was $27 \%$.

Finally, it remains to account for the demographic differences in the traditional versus SCALE-UP sections and the significant improvement of student grades that has already been established earlier. We saw that there were 
slightly higher percentages of males, black or African Americans, and accounting majors in the SCALE-UP sections as opposed to the traditional sections.

Table 5. First regression model with Math 112 grade (GPA) as response variable

\begin{tabular}{llll}
\hline Name & Estimate & t value & p value \\
\hline Intercept & -0.957 & -5.310 & $1.41 \mathrm{e}-07$ \\
Scaleup & 0.255 & 2.340 & 0.0195 \\
Before GPA & -0.849 & -5.592 & $3.05 \mathrm{e}-08$ \\
After GPA & 1.911 & 11.980 & $<2.0 \mathrm{e}-16$ \\
\hline
\end{tabular}

Note. Scaleup dummy variable significant at the level of $\mathrm{p}=0.0195$. The regression had 822 degrees of freedom, R-squared of 0.2882 , adjusted R-squared of 0.2856 . The F-statistic was 111 with a p-value of 2.2e-16.

Table 5 gives statistics from a regression analysis performed using Math 112 grade as the response variable and SCALE-UP dummy variable with before and after GPA. We see that before and after GPA are highly significant (better students do better) yet that does not change the significance of the SCALE-UP influence on student performance $(\mathrm{p}=0.0195)$.

A second regression analysis was performed which used gender, race, and student major. Traditional was the reference case for instructional method, accounting or finance was the reference case for major, female was the reference case, and other was the reference case for race. Table 6 gives statistics from the second regression analysis. The first regression had an R-squared of 0.2882 and adjusted R-squared of 0.2856 , whereas the second regression saw R-squared increase to 0.3117 and adjusted R-squared increase to 0.2981 .

When accounting for race, gender and major, the significance level of SCALE-UP is reduced to $(p=0.0452)$ which is still considered to be statistically significant. Race and gender were not found to be statistically significant but student's major selection was statistically significant. Some, but not all of the significance is explained by major selection.

Table 6. Second regression model with Math 112 grade (GPA) as response variable

\begin{tabular}{llll}
\hline Name & Estimate & t value & p value \\
\hline Intercept & -0.782 & -1.169 & 0.2427 \\
Scaleup & 0.218 & 2.006 & 0.0452 \\
Before GPA & -0.870 & -5.715 & $1.54 \mathrm{e}-08$ \\
After GPA & 1.903 & 11.855 & $<2.0 \mathrm{e}-16$ \\
Major=Other & -0.423 & -3.611 & 0.0003 \\
Major=Undeclared & -0.417 & -2.219 & 0.0268 \\
Major=Animal Science & -0.318 & -2.066 & 0.0392 \\
Major=Management & -0.166 & -1.297 & 0.1950 \\
Major=Marketing & -0.072 & -0.439 & 0.6606 \\
Gender=Male & 0.098 & 1.219 & 0.2234 \\
Race=Black & 0.127 & 0.202 & 0.8403 \\
Race=Hispanic & 0.141 & 0.213 & 0.8312 \\
Race=Two/More & 0.086 & 0.130 & 0.8964 \\
Race=White & -0.086 & -0.129 & 0.8973 \\
Race=Unknown & -0.166 & -0.235 & 0.8146 \\
\hline
\end{tabular}

Note. Scaleup dummy variable significant at the level of $\mathrm{p}=0.0452$. The regression had 809 degrees of freedom, R-squared of 0.3117 , adjusted R-squared of 0.2981 . The F-statistic was 22.9 with a p-value of 2.2e-16.

Accounting majors (including finance) were the highest performing students. Other business majors of management and marketing were not statistically significant, but the majors of animal science and "other" performed significantly worse. Other contains essentially many sets of students whose percentages fall below $3 \%$ of the overall population. This includes both "technology" majors, construction management, applied engineering technology, electronics technology, graphic design technology, and some students who were misplaced, transient, or seeking to change their major. The students in the other category were the worst performers overall with a grade an average of 0.423 points worse at a significance level of $(\mathrm{p}=0.0003)$. 


\section{Discussion and Future Work}

In this paper, we have reviewed the literature relevant to the educational theory behind active learning pedagogies. We discussed the rationale behind offering active learning sections versus traditional sections and why a mixture of the pedagogies is preferred. We illustrated a case study in which a section of a course was redesigned using active learning pedagogies and saw that students who selected that course prefer active learning pedagogies and that the mixture of instructional selection increased performance overall.

The students in the SCALE-UP sections performed better, with average course grade 0.27 points higher with a significance level of $p=0.0157$. This is in line with other studies that indicate an improvement in minority students' performance with active learning methodologies. We could not seriously say that active learning is a magic potion because the improved sections still have average grade point average of 2.17 and still have a DWF rate of $27 \%$, but we have shown that the utilization of the active learning method provides an improvement that is statistically significant.

We can positively conclude that minority students both prefer and perform better in an applied calculus course when using a SCALE-UP active learning strategy. Some future work will be undertaken to discover the so far undescribed qualities that lead more highly motivated students to enroll in active learning sections, and whether there is a feedback mechanism in which active learning enhances student engagement.

So far there is still no evidence or reasoning that supports one single strategy that serves as a sufficient condition for student success in general education mathematics courses, and it is accepted that active learning may lead to an increase in student success and learning, particularly among underserved communities. We contend that in order to facilitate student success, universities should offer course sections which provide a variety of instructional strategies.

\section{References}

Beichner, R. J. et al. (2007). The student-centered activities for large enrollment undergraduate programs (SCALE-UP) project. Research-based reform of university physics, 1(1), 2-39.

Bonwell, C. C., \& Eison, J. A. (1991). Active Learning: Creating Excitement in the Classroom. 1991 ASHE-ERIC Higher Education Reports. ERIC Clearinghouse on Higher Education, The George Washington University, One Dupont Circle, Suite 630, Washington, DC 20036-1183.

Chamberlin, M., \& Powers, R. (2010). The promise of differentiated instruction for enhancing the mathematical understandings of college students. Teaching Mathematics and Its Applications: An International Journal of the IMA, 29(3), 113-139. https://doi.org/10.1093/teamat/hrq006

Corno, L. Y. N. (2008). On teaching adaptively. Educational Psychologist, 43(3), 161-173. https://doi.org/10.1080/00461520802178466

Dougherty, D. (2012). The maker movement. Innovations: Technology, Governance, Globalization, 7(3), 11-14. https://doi.org/10.1162/INOV_a_00135

Eddy, S. L., \& Hogan, K. A. (2014). Getting under the hood: How and for whom does increasing course structure work? CBE Life Sci. Educ., 13(3), 453-468. https://doi.org/10.1187/cbe.14-03-0050

Edoh, K. D., Roop, J. P., Park, C., \& Ahmad, D. (2016). Calculus for Business and Technology. Pearson Publishing.

Edoh, K., Kurepa, A., \& Roop, J. P. (2017). Is Active Learning with Technology Changing Minority Students' Attitudes Towards Mathematics?. In P. Resta \& S. Smith (Eds.), Proceedings of Society for Information Technology \& Teacher Education International Conference 2017 (pp. 1359-1364). Chesapeake, VA: Association for the Advancement of Computing in Education (AACE).

Fischer, K. W., \& Rose, L. T. (2001). Webs of skill: How students learn. Educational Leadership, 59(3), 6-123.

Freeman, S., Eddy, S. L., McDonough, M., Smith, M. K., Okoroafor, N., Jordt, H., \& Wenderoth, M. P. (2014). Active learning increases student performance in science, engineering, and mathematics. Proceedings of the National Academy of Sciences, 111(23), 8410-8415. https://doi.org/10.1073/pnas.1319030111

Graham, M. J. et al. (2013). Increasing persistence of college students in STEM. SCIENCE, 341, 1455-1456. https://doi.org/10.1126/science.1240487

Green, F. R. (1999). Brain and learning research: Implications for meeting the needs of diverse learners. Education, 119(4), 682-688. 
Irvine, J. J., \& York, D. E. (1995). Learning Styles and Culturally Diverse Students: A Literature Review.

Jones, F. B. (1977).The Moore method. American Mathematical Monthly, 84(4), 273-278. https://doi.org/10.1080/00029890.1977.11994333

Kolb, A. Y., \& Kolb, D. A. (2005). Learning styles and learning spaces: Enhancing experiential learning in higher education. Academy of Management Learning \& Education, 4(2), 193-212. https://doi.org/10.5465/amle.2005.17268566

Lawrence-Brown, D. (2004). Differentiated instruction: Inclusive strategies for standards-based learning that benefit the whole class. American secondary education, 32(3), 34-62.

Marshall, D. C., Odell, E., \& Starbird, M. (2007). Number theory through inquiry. Mathematical Association of America.

Northcraft, G. B., \& Jernstedt, G. C. (1975). Comparison of four teaching methodologies for large lecture classes. Psychological reports, 36(2), 599-606. https://doi.org/10.2466/pr0.1975.36.2.599

Park, E. L., \& Choi, B. K. (2014). Transformation of classroom spaces: Traditional versus active learning classroom in colleges. Higher Education, 68(5), 749-771. https://doi.org/10.1007/s10734-014-9742-0

Ross, T. F. (2014). How black students tend to learn science: Transforming a lecture into a more active experience is one possible way of fixing STEM's diversity dilemma. The Atlantic. Retrieved Dec. 12, 2014, from http://www.theatlantic.com/education/archive/2014/12/how-black-students-tend-to-learn-science/383387/

Subban, P. (2006). Differentiated instruction: A research basis. International Education Journal, 7(7), 935-947.

Twigg, C. A. (2005). Increasing success for underserved students: redesigning introductory courses, The National Center for Academic Transformation. Retrieved from http://www.thencat.org/Monographs/IncSuccess.htm

\section{Copyrights}

Copyright for this article is retained by the author, with first publication rights granted to the journal.

This is an open-access article distributed under the terms and conditions of the Creative Commons Attribution license (http://creativecommons.org/licenses/by/4.0/). 